\title{
Collaboration Towards a More Inclusive Society: The Case of South African ICT4D Researchers
}

\author{
Judy van Biljon ${ }^{(\varpi)}$ (D) and Filistea Naude (D) \\ University of South Africa, Pretoria, South Africa \\ \{vbiljja, fnaude\}@unisa.ac.za
}

\begin{abstract}
In this study, research collaboration in the context of South African Information and Communication for Development (ICT4D) researchers was investigated using a mixed methods approach. South Africa, a country with stark development challenges and on the other hand a well-established ICT infrastructure, provides an appropriate context for ICT4D research. Firstly, a quantitative analysis of South African research collaboration between 2003 and 2016 was conducted to determine the existing research collaboration patterns of South African ICT4D researchers. This is based on the publications in three top ICT4D journals namely the Electronic Journal of Information Systems in Developing Countries (EJISDC), Information Technologies \& International Development (ITID), and Information Technology for Development (ITD). The results show that most co-authored papers were intra-institutional collaborations, with limited inter-institutional collaboration between South African authors or between South African and other African authors. Secondly, interviews were conducted with South African researchers who emerged as inter- and intra-institutional collaborators to gain insight into the technology, drivers and barriers affecting South African research collaboration. We report our findings and discuss the implications for employing research collaboration as a mechanism for addressing inequality and supporting inclusion.
\end{abstract}

Keywords: ICT4D $\cdot$ Research collaboration $\cdot$ Co-authoring

Research cooperation · South Africa

\section{Introduction}

There is a global trend towards multidisciplinary teams conducting collaborative research to address complex challenges and achieve objectives not feasible for independent entities working unaided [1]. The nature of technologies being used in development projects is dynamically evolving and ICT4D research needs to become more multidisciplinary than before [2]. National and international research collaboration and the inclusion of novice researchers is advocated for knowledge development, exchange and incentivized by government and agency funding. However, practical constraints such as time and funding, intellectual property rights and competition among researchers can inhibit collaboration [3, 4]. Collaboration has been defined as a mutually beneficial, well-defined relationship entered into by two or more individuals 
or organisations to achieve common goals [5,6]. Research collaboration can be defined as a two-way process where individuals and/or organizations share learning, ideas and experiences to produce joint scientific outcomes [7].

The political system of apartheid in South Africa (1948-1993) caused internal division and international isolation. Apartheid ended with democratic elections in 1994, and there has been many initiatives since to overcome the consequences of apartheid towards building a more equitable, inclusive society. Research collaboration including inter-institutional collaboration and international collaboration has potential for bridging divides and building national research capacity.

This paper investigates research collaboration in the context of ICT4D research in South Africa. The purpose of this study is to describe researcher collaboration by considering the drivers and barriers related to scholarly collaboration from the researchers' perspective, the patterns of collaborating and the uniquely South African characteristics that influence research collaboration. The research was conducted as a two phased, mixed method study involving a sequential quantitative-qualitative design. The first phase involved a review of South African ICT4D research collaboration based on the publications in EJISDC, ITD and ITID in the period 2003 to 2016. The second phase comprise interviews with researchers who were involved in the interinstitutional collaborations identified in phase one. Co-authoring is used as a proxy for research collaboration since most research collaborations involve co-authored publications. The contribution is to provide unique insights from the perspective of South African ICT4D researchers that could be generalized towards an improved understanding of South African research collaboration. The findings should be useful to individual researchers, research organizations, governments and international funding organizations.

\section{Research Collaboration in Context}

Research collaboration is advocated towards improving impact where research impact includes a range of impacts of different types, which may be of different levels of importance to various stakeholders [8]. This impact is measured by a number of criteria, including the quality of the research outputs, the funding associated with the research outputs and the related citations [9]. Research outputs, including publications, postgraduate qualifications or funding proposals are evaluated through a peer-review system of which the integrity relies on a social network of informed yet unbiased researchers. This suggests duel imperatives, a knowledge generation and dissemination imperative where close collaboration is necessary but also a collaboration aspect where the other researcher is proposed as an impartial examiner or referee of papers and funding proposals. The need for and importance of inter-institutional collaboration in South Africa (RSA) has been highlighted in a number of national documents.

Onyancha and Maluleka [10] investigated co-authorship and collaborative research in sub-Saharan Africa. Using the Clarivate Analytics Web of Science citation indexes, the fifteen most productive countries in terms of number of publications in the period 1995 to 2008, were selected. Continental collaboration among sub-Saharan African 
country researchers was found to be minimal, compared to international collaboration between foreign country researchers and sub-Saharan African country researchers.

Tiovanen and Ponomariov [11] investigated the structure of African research collaboration. Research papers with an African address published between 2005 and 2009 were retrieved using Clarivate Analytics Web of Science database and text mined with the Vantage Point software. Social Network analyses software UCINET was used to analyse the research collaboration networks. The co-authorship links data showed three distinct African collaborative research regions, i.e. Southern-Eastern, Western and Northern. Collaboration between African countries are weak and there is an absence of regional integration of collaborative research networks. In terms of international collaboration, Europe is the largest collaboration partner for Africa, followed by North Africa. South Africa and Nigeria were the strongest research countries and integrative hubs in their regions.

Pouris and Ho [12] investigated research collaboration in Africa by analysing coauthorship data from articles published between 2007 and 2011 and retrieved from Clarivate Analytics Web of Science database. Internationally collaborative articles increased from $52 \%$ to $58 \%$ for the period investigated. Collaborative authorship in Africa is substantially higher than the rest of the world with medical and natural resources being the main research focus areas of African research.

Sooryamoorthy [13] investigated collaboration of South African Scientists using South African science publications data from Clarivate Analytics Web of Science database for the years 2000, 2003 and 2005. A number of variables had an impact on the number of citations that a South African scientist receives, such as number of authors, number of foreign authors, collaboration type as well as the discipline and sector of the author. Citation rates were higher for publications that were co-authored. The publications with international collaboration and external-institutional collaboration had higher visibility and received more citations than internal institutional collaboration. For South African publications, the number of citations increased as the number of collaborators increased. International collaboration received more than double the citations that domestic collaborations received. About $80 \%$ of the publications came from the top seven universities in South Africa.

Sooryamoorthy [14] studied the relationship between publication productivity and collaboration of 204 South African Science academics and researchers at two KwaZulu-Natal higher education institutions during 2007 to 2008 using face-to-face interviews. Results showed that the number of research projects, the number of international collaborative projects, the duration of the collaborative projects, the number of the collaborators and the length of the collaboration had an impact on research productivity. Respondents preferred collaboration rather than working individually in the production of international research papers. International collaboration increased the chances of publication. The South African research funding and incentive system have an impact on collaboration, because the subsidies due to the non-South African collaborators are not paid (unless formal associations are recorded). Therefore, single authored papers are beneficial from a South African funding perspective.

Sooryamoorthy [15] studied the collaboration patterns of South African Scientists using data from the Clarivate Analytics Web of Science database for the period 2000, 2003 and 2005. Results indicate that collaborative research is a growing phenomenon 
among South African scientists, with scientists showing a preference for collaboration over single authored research. International collaboration is preferred over domestic collaboration. The productivity of South African Scientists were improved through collaboration. Factors such as the number of authors and the number of countries involved had an impact on collaboration. Authors from Europe and secondly North America were the preferred collaborators for South African Scientists.

Boshoff [16] studied collaboration among the 15 countries of the Southern African Development Community (SADC) as well as between SADC and the rest of Africa for the period 2005 to 2008 . SADC researchers collaborate more with international highincome developed countries (47\% of SADC papers) than with African researchers. Only $3 \%$ of SADC papers were jointly authored by researchers from two or more SADC countries and only $5 \%$ of SADC papers were a collaboration with researchers from African countries outside SADC. South Africa is the leading country in terms of research output ( $81 \%$ papers), with the highest publication productivity of the SADC countries, and $78 \%$ of intra-regional co-authored papers.

The collaboration patterns of 50 African countries were studied for the period 2000-2012 using data from the Clarivate Analytics InCites Research Performance profiles database [17]. Finding indicate that South Africa is the research hub of Africa. The USA is the country that collaborated the most with Africa while the UK, Germany and France are the European countries that African countries collaborate with the most.

An ICT4D scholarly research collaboration study [18] revealed that $66 \%$ of the articles published in the EJISDC between 2000 and 2013 were co-authored articles. The collaboration patterns of the EJISDC showed that $32 \%$ of articles were intrainstitutional collaboration, $45 \%$ were national collaboration and $20 \%$ were international collaboration. Most of the EJISDC authors were from Africa, followed by Asia, North America and Europe. Most of the African authors, were from South Africa (37\%).

The effectivity of South African researchers in converting ICT4D research activity into significant research outputs were investigated by Turpin [19], who concluded that South Africa has a prominent presence in ICT4D journals, but this prominence is concentrated in one research institution and one ICT4D journal.

A study mapping the research collaboration networks in computer science for the UbuntuNet region (central, eastern and southern African Countries) identified the top five countries based on the number of publications as South Africa (77.64\%), Kenya (6.9\%), Ethiopia (3.8\%), Tanzania (3.32\%) and Uganda (3.14\%) respectively [20]. The results showed a high degree of collaboration with $88 \%$ of the publications multiauthored. However, collaboration with intra-collaboration of research within UbuntuNet region is low if compared to the inter-collaboration between countries in UbuntuNet region and other countries outside Africa [20].

In summary, the findings from the studies on research collaboration in Africa concur that South Africa is a key player on the African research landscape; there is a high degree of collaboration but the collaborations are mostly intra-institutional or with countries outside Africa. There is evidence supporting research collaboration as a factor improving productivity and increasing researchers' visibility in terms of citations. Notably, the top 7 universities in South Africa contributed $80 \%$ of the African research [13]; this underlines the importance of inter-institutional research for building South African research capacity. 


\section{Research Design}

Mixed methods research is a methodology framed around the idea of gathering and analysing both quantitative and qualitative data and integrating or combining the two datasets for further analysis [21]. This methodology was considered appropriate for this study since we needed to present the current research collaboration and gain insight on the drivers of collaboration behavior. A bibliometric analysis was used to quantify the existing research collaboration and we then aimed to explain that through insights gained from interviews (guided by structured, open-ended questions) with selected ICT4D researchers. The procedures followed are outlined in more detail below.

\subsection{Study 1: Quantification of South African Research Collaboration}

Data were collected from the top three ICT4D journals as identified by Heeks [22] namely: Electronic Journal of Information Systems in Developing Countries (EJISDC), Information Technologies \& International Development (ITID), and Information Technology for Development (ITD). The journal details and publishing information are depicted Table 1. The starting years of the three journals differ, and therefore only papers published between 2003 and 2016 were selected.

Table 1. Journal information

\begin{tabular}{l|l|l|l}
\hline Journal & $\begin{array}{l}\text { Electronic Journal of } \\
\text { Information Systems in } \\
\text { Developing Countries } \\
\text { (EJISDC) }\end{array}$ & $\begin{array}{l}\text { Information } \\
\text { Technologies \& } \\
\text { International } \\
\text { Development (ITID) }\end{array}$ & $\begin{array}{l}\text { Information } \\
\text { Technology for } \\
\text { Development } \\
\text { (ITD) }\end{array}$ \\
\hline $\begin{array}{l}\text { Journal } \\
\text { webpage }\end{array}$ & http://www.ejisdc.org & http://itidjournal.org/ & $\begin{array}{l}\text { http://www. } \\
\text { tandfonline.com/ } \\
\text { loi/titd20 }\end{array}$ \\
\hline Volume & $11-77$ & $1-12$ & $\begin{array}{l}10-22 \text { (Zero } \\
\text { articles published } \\
\text { in 2004) }\end{array}$ \\
\hline $\begin{array}{l}\text { Start } \\
\text { year }\end{array}$ & 2000 & 2003 & 1986 \\
\hline ISSN & ISSN: $1681-4835$ & ISSN: 1544-7529 & ISSN: 0268-1102 \\
\hline $\begin{array}{l}\text { Open } \\
\text { access }\end{array}$ & Open Access & Open Access & Not Open Access \\
\hline Publisher & $\begin{array}{l}\text { City University of Hong } \\
\text { Kong }\end{array}$ & $\begin{array}{l}\text { USC Annenberg School } \\
\text { for Communication }\end{array}$ & Taylor \& Francis \\
\hline
\end{tabular}

Naude [23] maintains that the coverage and indexing of ICT4D journals in the citation enhanced databases Web of Science and Scopus are inadequate, and coverage in commercial subject databases limited. Bibliometric, citation and South African authorship data for the selected the ICT4D journals listed in Table 1 were not available (or only partially available) in the traditional citation-enhanced platforms Web of 
Science and Scopus. The bibliographic data for EJISDC and ITD were exported from the Inspec database (IET) and the ITID data from EBSCOhost Business Source Complete database. The data for the three journals were exported into MS Excel format for analysis. The bibliographic data for the three journals combined comprised 1064 items. The data was collected in July 2017. The contents pages of the published journals were compared to the bibliographic data downloaded from the Inspec and EBSCOhost Business Source databases. Only research articles were included, and other article types such as editorial introductions, book reviews, etc. were omitted.

The data extracted from the databases provided the following information for each journal: title of paper, authors, year, volume, issue, author affiliation. The following information was added manually on the spreadsheet: total number of authors, number of countries involved in each paper, country affiliation of the authors and collaboration type.

The author affiliation data was used to identify the South African authored papers. A paper was classified as South African if there was at least one South African author. In cases where authors had more than one affiliation, the South African affiliation was used as the primary affiliation. After the data was collected per journal, the total number of volumes, issues, number of articles, number of South African authored articles and number of South African authors were calculated per annum as shown in tables 2 to 4 [24]. A list of the 103 South African authored papers published in the EJISDC, ITID and ITD can be viewed at [24].

Articles with South African authors were categorized into the three collaboration types: Intra-institutional (authors from the same institution collaborating), Interinstitutional (authors from different institutions collaborating) and International collaboration (authors from different countries collaborating).

\subsection{Study 2: Qualitative Investigation into the Drivers, Barriers and Incentives}

During the months of September to December 2017, interviews were conducted with 10 South African researchers involved in inter- and intra-collaborative research. Ethical clearance for this research was obtained from the Research and Ethics Committee in the School of Computing at the University of South Africa. The interview was structured according to the questionnaire provided as Appendix B [24]. The aim of the interview was to gain insight about the drivers of and barriers to collaboration as well as what would be perceived as useful incentives.

\section{Results and Findings}

\subsection{Study 1: South African Research Collaboration}

To contextualize South African ICT4D research, Tables 2, 3 and 4 (see Appendix A can be viewed at [24]) provide the number of South African papers (based on South African author affiliation), compared to the total number of papers. Despite the limitations inherent in any snapshot, this provides evidence of an increasingly active 
ICT4D research community in South Africa, which justifies the selection of this community for analyzing research collaboration. The results provide a profile of South African ICT4D research and shows initial low participation of South African researchers with a steady growth of South African authored papers in the last 6 years (2010 to 2016).

- Table 2 depicts the results for EJISDC. Of the 468 articles published between 2003 and 2016, 62 (13.24\%) articles were contributed by 128 South African authors [24].

- Table 3 shows the results for ITD. Notably of the 271 articles published between 2003 and 2016, 24 (8.85\%) articles were contributed by 42 South African authors [24].

- Table 4 depicts the results for the ITID. Of the 325 articles published between 2003 and 2016, 17 (5.23\%) articles were contributed by 23 South African authors [24].

Table 2 shows the collaboration patterns of South African authors in the three selected ICT4D journals. The results indicate that for the EJISDC, only $10(16.13 \%)$ of the 62 articles were single authored, compared to $52(83.88 \%)$ that were multi authored. The South African EJISDC collaboration patterns show that of the 52 articles, intra-institutional collaboration was the highest with $30(48.38 \%)$ articles, followed by international collaboration with 13 (20.97\%) articles and inter-institutional with $9(14.52 \%)$ articles. Of the 13 internationally collaborated articles, South African authors were first authors in 6 of the articles.

Table 2. Collaboration patterns of South African (RSA) ICT4D authors

\begin{tabular}{l|l|l|l|l|l|l}
\hline $\begin{array}{l}\text { Collaboration } \\
\text { type }\end{array}$ & $\begin{array}{l}\text { EJISDC no of } \\
\text { RSA articles }\end{array}$ & $\%$ & $\begin{array}{l}\text { ITID no of } \\
\text { RSA } \\
\text { articles }\end{array}$ & $\%$ & $\begin{array}{l}\text { ITD no of } \\
\text { RSA } \\
\text { articles }\end{array}$ & $\%$ \\
\hline Single author & 10 & 16.13 & 8 & 47.05 & 5 & 20.83 \\
\hline $\begin{array}{l}\text { Intra- } \\
\text { institutional }\end{array}$ & 30 & 48.38 & 3 & 17.64 & 8 & 33.33 \\
\hline $\begin{array}{l}\text { Inter- } \\
\text { institutional }\end{array}$ & 9 & 14.52 & 1 & 5.88 & 1 & 4.18 \\
\hline International & 13 & 20.97 & 5 & 29.43 & 10 & 41.66 \\
\hline Total & $\mathbf{6 2}$ & $\mathbf{1 0 0}$ & $\mathbf{1 7}$ & $\mathbf{1 0 0}$ & $\mathbf{2 4}$ & $\mathbf{1 0 0}$ \\
\hline
\end{tabular}

For the ITID, $8(47.05 \%)$ of the 17 articles were single authored, compared to 9 $(52.95 \%)$ that were multi authored. Of the South African ITID collaborated articles, international collaboration was the highest with 5 (29.43\%) articles, followed by intrainstitutional collaboration with $3(17.64 \%)$ articles and inter-institutional with 1 $(5.88 \%)$ article. Of the 5 internationally collaborated articles, South African authors were first authors in 4 of the articles.

For the ITD, $5(20.83 \%)$ of the 24 articles were single authored, compared to 19 $(79.17 \%)$ that were multi authored. Of the South African ITD collaborated articles, international collaboration was the highest with $10(41.66 \%)$ articles, followed by intrainstitutional collaboration with $8(33.33 \%)$ articles and inter-institutional with 1 
$(4.18 \%)$ article. Of the 10 internationally collaborated articles, South African authors were first authors in 7 of the articles.

Collectively, looking at the EJISDC, ITD and ITID combined; of the 1064 articles published between 2003 and 2016, 103 (9.68\%) articles were contributed by 193 South African authors. Of the 103 South African authored articles, $23(22.33 \%)$ articles were single authored and $80(77.67 \%)$ multi authored. Of the 80 collaboratively authored South African articles, 41 (51.25\%) were intra-institutional collaboration, 28 (35\%) were international collaboration and $11(13.75 \%)$ were inter-institutional collaboration. Of the 28 internationally collaboratively authored South African articles, South African authors were first authors in $17(60.71 \%)$ of the articles.

Table 3 compares the South African authorship patterns of the three journals in this study. The data from the EJISDC and ITD show that the most common collaboration is between two South African authors, followed by 3 authors and then single authorship. In contrast the ITID journal analysis indicates that single authorship is the most popular followed by two authors collaborating.

Table 3. Authorship patterns of South African (RSA) ICT4D authors

\begin{tabular}{l|l|l|l|l|l|l}
\hline Authorship & $\begin{array}{l}\text { EJISDC no of } \\
\text { RSA articles }\end{array}$ & $\%$ & $\begin{array}{l}\text { ITID no of } \\
\text { RSA articles }\end{array}$ & $\%$ & $\begin{array}{l}\text { ITD no of } \\
\text { RSA articles }\end{array}$ & $\%$ \\
\hline 1 author & 10 & 16.14 & 8 & 47.07 & 5 & 20.83 \\
\hline 2 authors & 30 & 48.39 & 6 & 35.29 & 8 & 33.33 \\
\hline 3 authors & 15 & 24.19 & & & 8 & 33.33 \\
\hline 4 authors & 5 & 8.06 & 2 & 11.76 & 2 & 8.33 \\
\hline 5 authors & 1 & 1.61 & 1 & 5.88 & & \\
\hline 6 authors & 1 & 1.61 & & & & \\
\hline 7 authors & & & & & 1 & 4.18 \\
\hline Total & $\mathbf{6 2}$ & $\mathbf{1 0 0}$ & $\mathbf{1 7}$ & $\mathbf{1 0 0}$ & $\mathbf{2 4}$ & $\mathbf{1 0 0}$ \\
\hline
\end{tabular}

Collectively, when EJISDC, ITD and ITID are combined; of the 103 authored South African articles published between 2003 and 2016, there were 23 single authorship articles, 44 articles with 2 authors, 23 articles with 3 authors, 9 articles with 4 authors, 2 articles with 5 authors, 1 articles with 6 authors and 1 article with 7 authors. This shows that the most common authorship pattern is collaboration between 2 South African authors.

An analysis of the countries that South African ICT4D researchers collaborated with in the period 2003 to 2016, are depicted in Table 4. South Africa collaborated internationally on 28 articles. South Africa collaborated the most with other authors from the African region, showing the 7 African countries below. The second biggest regional collaboration partner for South African was Europe, with 6 European countries co-authoring articles with South African researchers. South African researchers also collaborated with North America (USA and Canada) as well as Oceania (New Zealand and Australia). The lowest collaboration was in the regions Asia (India) and Latin America (Brasil). There was no collaboration between South Africa and the Middle East region. 
Table 4. Country Collaboration patterns of South African ICT4D authors

\begin{tabular}{l|l|l|l|l|l|l}
\hline Country & $\begin{array}{l}\text { EJISDC } \\
\text { no of } \\
\text { articles }\end{array}$ & $\begin{array}{l}\text { EJISDC } \\
\text { no of } \\
\text { authors }\end{array}$ & $\begin{array}{l}\text { ITID no } \\
\text { of } \\
\text { articles }\end{array}$ & $\begin{array}{l}\text { ITID no } \\
\text { of } \\
\text { authors }\end{array}$ & $\begin{array}{l}\text { ITD no } \\
\text { of } \\
\text { articles }\end{array}$ & $\begin{array}{l}\text { ITD no } \\
\text { of } \\
\text { authors }\end{array}$ \\
\hline
\end{tabular}

Region: Africa

\begin{tabular}{l|l|l|l|l|l|l} 
Namibia & 2 & 2 & 1 & 1 & & \\
\hline Nigeria & 1 & 2 & & & & \\
\hline Uganda & & & 1 & 1 & & \\
\hline Tunisia & & & & & 1 & 1 \\
\hline Ghana & & & & & 1 & 2 \\
\hline Malawi & & & & & 1 & 2 \\
\hline Zimbabwe & $\mathbf{1}$ & $\mathbf{1}$ & & & & \\
\hline
\end{tabular}

Region: Europe

\begin{tabular}{l|l|l|l|l|l|l}
\hline Finland & 1 & 1 & & & & \\
\hline Norway & & & & & 2 & 2 \\
\hline Italy & & & & 1 & 1 \\
\hline Ireland & & & & 1 & 1 \\
\hline Netherlands & & & & 1 & 1 \\
\hline UK & 1 & 1 & 1 & 1 & 3 & 5 \\
\hline
\end{tabular}

Region: North America

\begin{tabular}{l|l|l|l|l|l|l}
\hline USA & 2 & 3 & 3 & 5 & 3 & 3 \\
\hline Canada & 1 & 1 & & & &
\end{tabular}

Region: Oceania

\begin{tabular}{l|l|l|l|l|l|l}
\hline $\begin{array}{l}\text { New } \\
\text { Zealand }\end{array}$ & 1 & 1 & & & & \\
\hline Australia & 2 & 2 & & & & \\
\hline Region: Asia & 1 & 1 & 1 & 1 & & \\
\hline India & 1 &
\end{tabular}

Region: Latin America

Brasil

\begin{tabular}{l|l|l}
1 & 1
\end{tabular}

Based on the inter and intra-institutional publications identified in EJISDC, ITD and ITID respectively, 10 of the authors involved in inter-institutional collaborative publications were interviewed. The questionnaire is available in Appendix B [24]. The next section presents the findings from the interviews providing some insights towards understanding research collaboration drivers and barriers.

\subsection{Study 2: Explaining South African Research Collaboration}

The interviews were conducted telephonically or via online digital communication (Skype voice only). All of the 10 South African interviewees had doctoral degrees and have been involved in inter- and intra-collaborative research. Four of the authors were no longer involved in inter-institutional collaborations due to one or more of the following barriers mentioned by the interviewees: Lack of funding, lack of awareness 
of opportunities or access to suitable collaborators, administrative procedures and lack of administrative support. Researcher assessment focuses on the numbers (quantity rather than the quality of the outputs) [25]. In the South African funding model, research credit is divided by the number of authors. In the case of foreign researchers, the money related to the credit is not paid to them or transferred to the collaborating South African researchers. Additional factors include cultural differences in terms of time management, attitudes, work ethic and practices, competition and the lack of overarching, longer-term projects.

Interviewees mentioned the following drivers of research collaboration: Access to funding, complementary skills (strategic, technical or methodological), access to new collaboration networks and data, personal connections, similar work ethics and willingness to compromise. Usefulness in terms of career and profile building (CV).

Based on studies in the fields of health, social science, education and public affairs, 19 factors that influence the success of research collaborations were identified and grouped those into six categories, namely environment, membership, process/structure, communication, purpose and resources [6]. Considering the results in terms of these categories it becomes clear that the drivers and barriers often depict different aspects of the same factor. The interview data will now be unpacked in terms of these categories. The participants did not mention all of the 19 issues identified previously. That does not detract from their relevance since participants may simply not have thought about that at the time. Therefore all 19 issues were retained while those that emerged from the interviews are now discussed in more detail.

Environment (geographic location and social context): The factors previously identified as conducive were a history of collaboration, the collaborators being seen as leaders in the research community and a favorable political/social climate.

- Participants\#2, 3, 7 and 9 confirmed the necessity for a favorable political and social climate.

- Participant\#9 mentioned that lip-service was being paid to collaboration while the administrative and financial support was lacking.

- Due to the isolation caused by apartheid there was no history of collaboration and that accounts for the responses indicating a lack of awareness on where to start collaborations (Participant\#6).

\section{Membership}

- Participants\#1, 6 and 11 mentioned mutual respect, understanding and trust,

- Participants\#1, 4, 5 mentioned the need for an appropriate cross section of members,

- Participant\#10, mentioned the need to see collaboration as in the individual's selfinterest) and personally felt that collaboration was not worth the effort so the individual stopped collaborating,

- Participant\#7 mentioned the individual's ability to compromise

- Participant\#8 mentioned feelings of inferiority towards researchers from developed countries that was intensified by their behavior 


\section{Process/structure}

- Participant\#1 mentioned administration but none of the participants unpacked the details in terms of the other factors including members share a stake in both process and outcome, multiple layers of decision-making, flexibility, development of clear roles and policy guidelines and adaptability.

- Participant\#5 mentioned the need for longer term projects needed to address complex problems that attract multi-disciplinary and highly rated researchers.

\section{Communication}

None of the participants specifically mentioned open and frequent communication or established informal and formal communication links but language was mentioned as a barrier for those who were not first language English speakers (Participant\#6).

\section{Purpose}

Participant\#2 mentioned a shared vision and context. Concrete, attainable goals and objectives and a unique purpose were implicit in the drivers but not formulated as such.

\section{Resources}

All the participants mentioned funding, either as a driver of research collaboration or lack thereof as a barrier. Furthermore, Participants\#4 and 8 mentioned access to data, infrastructure and collaboration networks as drivers. The researchers used the Internet, email, text messages and Voice-over-Internet technologies for their collaboration. Citation management systems and software packages for quantitative and qualitative analysis were also used with a preference for open source systems.

In summary, the unique South African collaboration factor that emerged pertain to the lack of a collaboration history. This manifests in terms of a lack of personal collaboration goals, lack of awareness of collaboration opportunities, lack of collaboration skills and perceptions of inferiority towards researchers from developed countries. The latter may be unintentionally strengthened by cultural differences. Another important issue is that the South African funding model incentivizes single authored papers. Personality and cultural factors are subjective, but notably more than one researcher mentioned openness and a 'can do' attitude as South African traits.

\section{Conclusion}

Our results show that most of the South African authored ICT4D articles were coauthored EJISDC (83.87\%), ITID (52.95\%) and ITD (79.17\%). Most of the collaborations $(65 \%)$ were national collaboration (i.e. between South Africans), most of those were with authors in the same institution (51.25\% intra-institutional) with the number of inter-institutional collaborations $(13.75 \%)$ being very low. This suggests that interinstitutional collaboration on the South African authored articles is limited. These findings on ICT4D collaboration corresponds with previous research on collaboration patterns for South African authors and signals a potential research capacity building barrier. Due to historical segregation there are large discrepancies between the research capacities of the different South African institutions; therefore promoting research collaboration as a mechanism of inclusion is important. Considering the drivers of 
collaboration, access to funding and resources, knowledge gains and building an international profile was found to be important. The main barriers were reported to be funding, time and lack of administrative support in managing grants. The fact that these were all established researchers could influence the responses but it was necessary to interview researchers with proven experience in collaborating. The findings corroborate the relevance of most of the collaboration factors previously identified. The contribution of this paper is to confirm that the general findings on collaboration patterns apply to ICT4D researchers; thus their perceptions on research collaboration can be considered as a point of departure in explaining South African research collaboration. The second contribution is to provide insights on the uniquely South African factors that influence collaboration from the ICT4D researcher's perspective. More research is needed to include the views of emerging researchers and to compare the findings with research collaboration patterns in other African countries.

\section{References}

1. Anandarajan, A., Anandarajan, M.: An overview of e-Research collaboration. In: Anandarajan, A., Anandarajan, M. (eds.) e-Research Collaboration, pp. 3-13. Springer, Heidelberg (2010). https://doi.org/10.1007/978-3-642-12257-6_1

2. Zheng, Y., Hatakka, M., Sahay, S., Andersson, A.: Conceptualizing development in information and communication technology for development (ICT4D). Inf. Technol. Dev. 24, 1-14 (2017)

3. Sonnenwald, D.H.: Scientific collaboration. Ann. Rev. Inf. Sci. Technol. 41, 643-681 (2007)

4. Wagner, C.: International collaboration in science and technology: promises and pitfalls. In: Science and Technology Policy for Development. Dialogues at the Interface, pp. 165-176 (2006)

5. Sooryamoorthy, R.: Scientific collaboration in South Africa. S. Afr. J. Sci. 109, 1-5 (2013)

6. Mattessich, P., Murray-Close, M., Monsey, B.: Collaboration: What Makes It Work: A Review of Research Literature on Factors Influencing Successful Collaboration, 2nd edn. Amherst H. Wilder Foundation, Saint Paul (2001)

7. Cataldi, M., Di Caro, L., Schifanella, C.: Ranking researchers through collaboration pattern analysis. In: Berendt, B., et al. (eds.) ECML PKDD 2016. LNCS (LNAI), vol. 9853, pp. 5054. Springer, Cham (2016). https://doi.org/10.1007/978-3-319-46131-1_11

8. Neylon, C., Willmers, M., King, T.: Rethinking impact: applying altmetrics to Southern African research. Scholarly Communication in Africa Programme, pp. 1-20 (2013)

9. Von Solms, R., Von Solms, B.: Publish or perish ... but where? S. Afr. Comput. J. 28, 1-11 (2010)

10. Onyancha, O.B., Maluleka, J.R.: Knowledge production through collaborative research in sub-Saharan Africa: how much do countries contribute to each other's knowledge output and citation impact? Scientometrics 87, 315-336 (2011)

11. Toivanen, H., Ponomariov, B.: African regional innovation systems: bibliometric analysis of research collaboration patterns 2005-2009. Scientometrics 88, 471-493 (2011)

12. Pouris, A., Ho, Y.-S.: Research emphasis and collaboration in Africa. Scientometrics 98, 2169-2184 (2014)

13. Sooryamoorthy, R.: Do types of collaboration change citation? Collaboration and citation patterns of South African science publications. Scientometrics 81, 177-193 (2009) 
14. Sooryamoorthy, R.: Publication productivity and collaboration of researchers in South Africa: new empirical evidence. Scientometrics 98, 1-15 (2014)

15. Sooryamoorthy, R.: Collaboration and publication: how collaborative are scientists in South Africa? Scientometrics 80, 419-439 (2009)

16. Boshoff, N.: South-South research collaboration of countries in the Southern African Development Community (SADC). Scientometrics 84, 481-503 (2010)

17. Adams, J., Gurney, K., Hook, D., Leydesdorff, L.: International collaboration clusters in Africa. Scientometrics 98, 547-556 (2014)

18. Naude, F.: Country trends and scholarly collaboration in the ICT4D research community 2000-2013: a single journal study. Electron. J. Inf. Syst. Dev. Ctries. 72, 1-26 (2016)

19. Turpin, M.: Assessing South African ICT4D research outputs: a journal review. S. Afr. Comput. J. 30, 108-127 (2018)

20. Marwa, C.W., Sangeda, R.Z., Lwoga, E.T.: Mapping the research collaboration networks in computer science: the case of central, eastern and southern African Countries. In: UbuntuNet Connect 2017, Addis Ababa (2017)

21. Creswell, J.W., Clark, V.L.P.: Designing and Conducting Mixed Methods Research. Sage Publications Ltd., Washington, D.C. (2011)

22. Heeks, R.: Theorizing ICT4D research. Inf. Technol. Int. Dev. 3, 1-4 (2007)

23. Naude, F.: Electronic journal of information systems in developing countries (2000-2013): a bibliometric study. Electron. J. Inf. Syst. Dev. Ctries. 72, 1-23 (2016)

24. Naude, F., van Biljon, J.: South African ICT4D papers 2003-2016. https://figshare.com/ articles/South_African_ICT4D_papers_2003_-_2016/5769099

25. Visser, G.: On citations, rating games and other pesky animals: which zoo for South African human geography? S. Afr. Geogr. J. 89, 135-144 (2007) 